\title{
LAPAROSCOPIC APPROACH IN THE OVARIAN VEIN SYNDROME
}

\author{
ARAKÉN ALMEIDA, FRANCISCO CAVALCANTI, SÁVIO BARBOSA, ROBERTO COHEN, \\ AMAURY MEDEIROS
}

\author{
Oswaldo Cruz University Hospital, Pernambuco University, Recife, Pernambuco, Brazil
}

\begin{abstract}
Introduction: The main objective of this article is to describe ureterolysis and ovarian vein resection laparoscopic technique.

Surgical technique: With the patient in a $45^{\circ}$ flank position, 3 trocars are used, 1 of $12 \mathrm{~mm}$ in the umbilicus for the optic passage, and 2 of 5 and $10 \mathrm{~mm}$ inserted in right hypochondrium and iliac fossa, respectively, for the forceps and stapler passage. The ureter and ovarian vein are identified after the mobilization of the colon. Both structures are dissected, with one ovarian vein segment is resected between metallic clips.

Comments: the ureteral approach by transperitoneal laparoscopy and colon mobilization facilitates its dissection, identify its relation to other structures, as well as making possible the concomitant treatment of gynecological diseases. For the ovarian syndrome treatment, ureterolysis and ovarian vein resection are performed, using only 3 trocars. Owing to its simplicity, low morbidity, and good results obtained, this procedure represents a good option for the surgical management of this syndrome.
\end{abstract}

Key words: laparoscopy; ovary; veins; syndrome; therapeutics

Int Braz J Urol. 2003; 29: 45-7

\section{INTRODUCTION}

The therapeutic procedure for the ovarian vein syndrome varies according to the intensity and urgency of the clinic presentation. In nulliparous women, non-pregnant multiparous women and in children, the treatment is conservative. Yet, pregnancy may promote an intensification of this condition, leading to the necessity of a surgical intervention (1). We present case report of 1 ovarian vein syndrome treated by laparoscopic approach, with surgical technique description.

\section{CASE REPORT AND SURGICAL TECHNIQUE}

A 26 years-old patient, $62 \mathrm{~kg}, 1.68 \mathrm{~m}$ (BMI = 22 ), with right lumbar pain and 8 months recurrent urinary tract infections complaints, also with obstetric history of 3 gestations, was submitted to ureterolysis and right ovarian vein laparoscopic resection in our Unit, using the technique described as follows. Diagnosis was established by intravenous pyelogram and computed tomography (Figures-1 and 2).

Surgical technique: With the patient in a $45^{\circ}$ flank position, a $15 \mathrm{~mm}$ incision is performed in the umbilical area, including skin and aponeurosis. After the peritoneum incision, the Hasson trocar is inserted and fixed, allowing the $0^{\circ}$ optic passage. Insufflation is initiated, maintaining the pneumoperitoneum under a pressure of 12 to $15 \mathrm{~mm} \mathrm{Hg}$. Under direct vision, 2 trocars of 5 and $10 \mathrm{~mm}$ are also inserted at the level of the right midclavicular line, in hypochondrium and iliac fossa, respectively, admitting forceps and stapler passage. The surgical table is rotated laterally, maintaining the patient in a $45^{\circ}$ left lateral decu- 


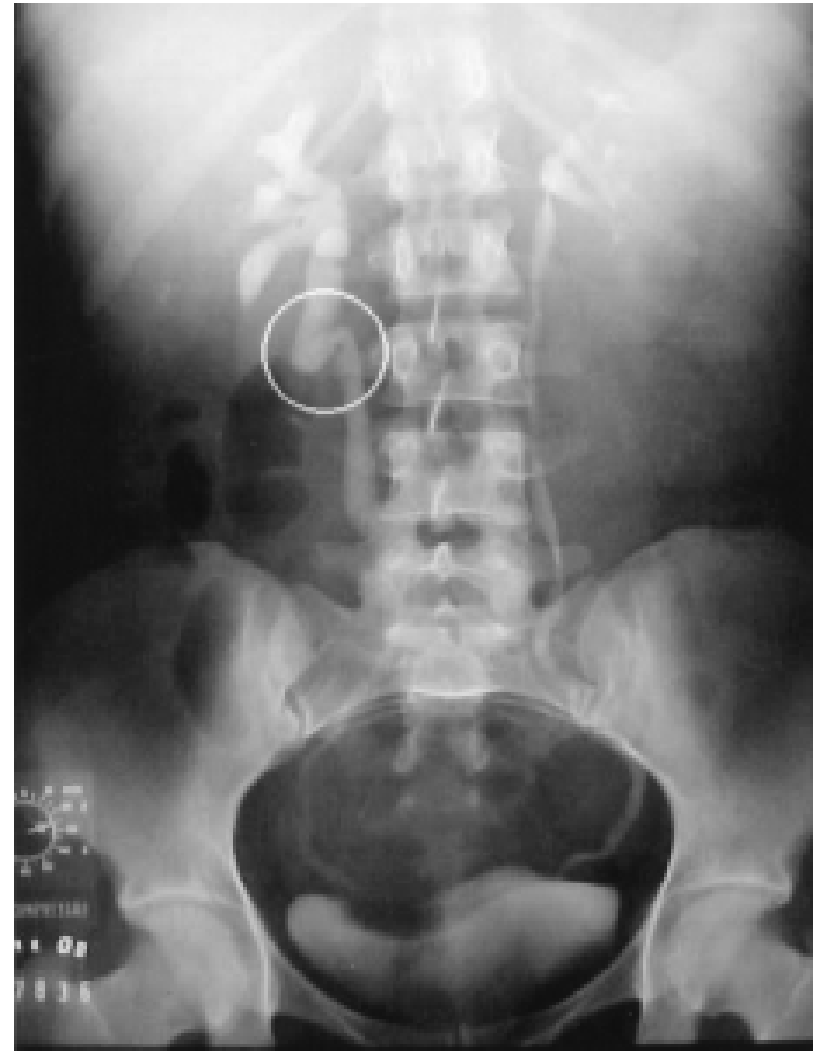

Figure 1 - Intravenous pyelogram showing dilation and tortuosity of the upper ureter (circle) and dilation of the right pyelocalyceal system.

bitus. The incision in the Toldt line is performed, mobilizing the colon medially. The ovarian vein plexus is identified, considering its course and relation to the ureter. Both structures are dissected, releasing the ureter and isolating the ovarian vein plexus, in a sufficient extension for its transection between metallic clips, approximately $2 \mathrm{~cm}$ above and below where it cross the ureter. The segment of the ovarian vein is pulled out, and then both trocars are removed under direct vision.

The pneumoperitoneum is reverted and the $10 \mathrm{~mm}$ aponeurosis incisions are sutured with absorptive suture. The adhesive plaster is placed over the incisions after the skin is sutured with intradermic stitches.

The procedure was performed in 45 minutes. Per- and postoperative period were uneventful, and the patient progressed well, without analgesic requirements in the immediate postoperative period, being discharged 36 hours after surgery. In a follow-up of 18 months, the patient remained asymptomatic, with negative uroculture results every 3 months and with no radiologic signs of ureteral obstruction (Figure$3)$.

\section{COMMENTS}

In the ovarian vein syndrome, the symptoms appear usually in multiparous women, being unusual in nuliparous women and children. It may also occur during or immediately after labor, and in non-pregnant women before menstrual period (2).

In 1996, Elashry et al. (3) published the results of 6 patients with benign extrinsic ureteral obstruction, submitted to successful ureterolysis by

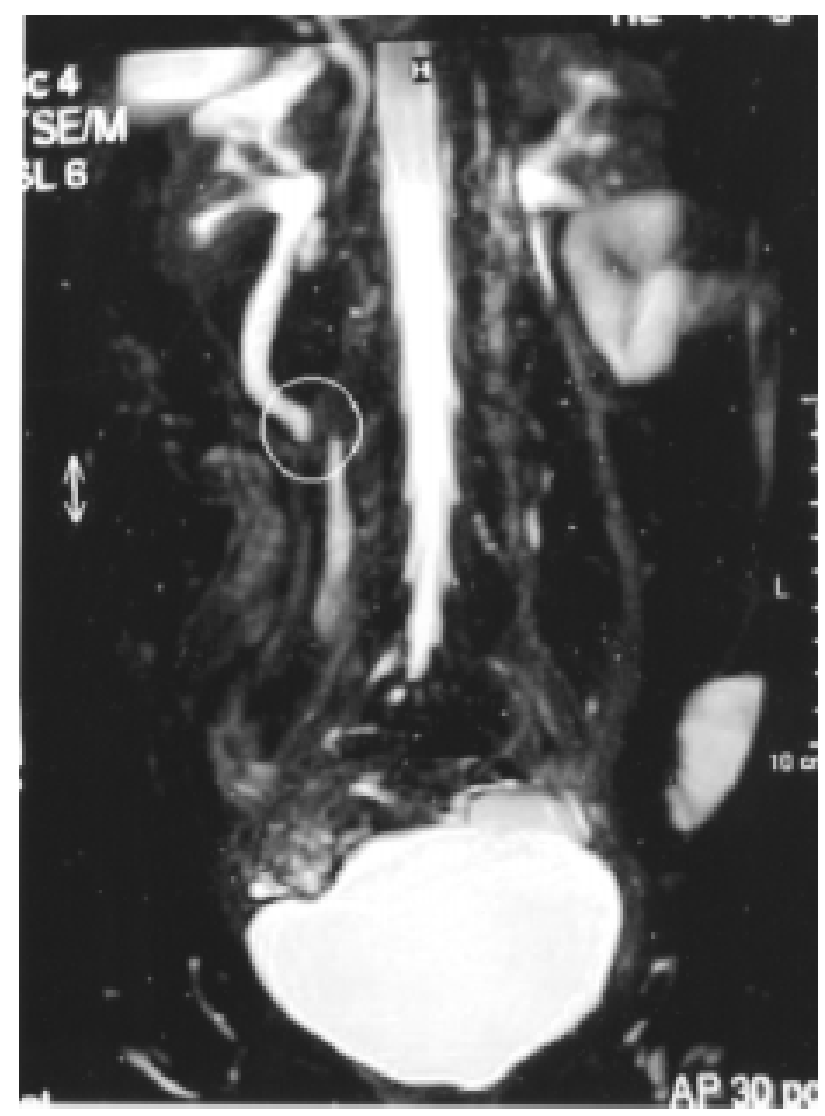

Figure 2 - Computed tomography showing dilatation with filling defect of the right upper ureter (circle), and dilation of the right pyelocalyceal system. 


\section{LAPAROSCOPIC APPROACH IN THE OVARIAN VEIN SYNDROME}

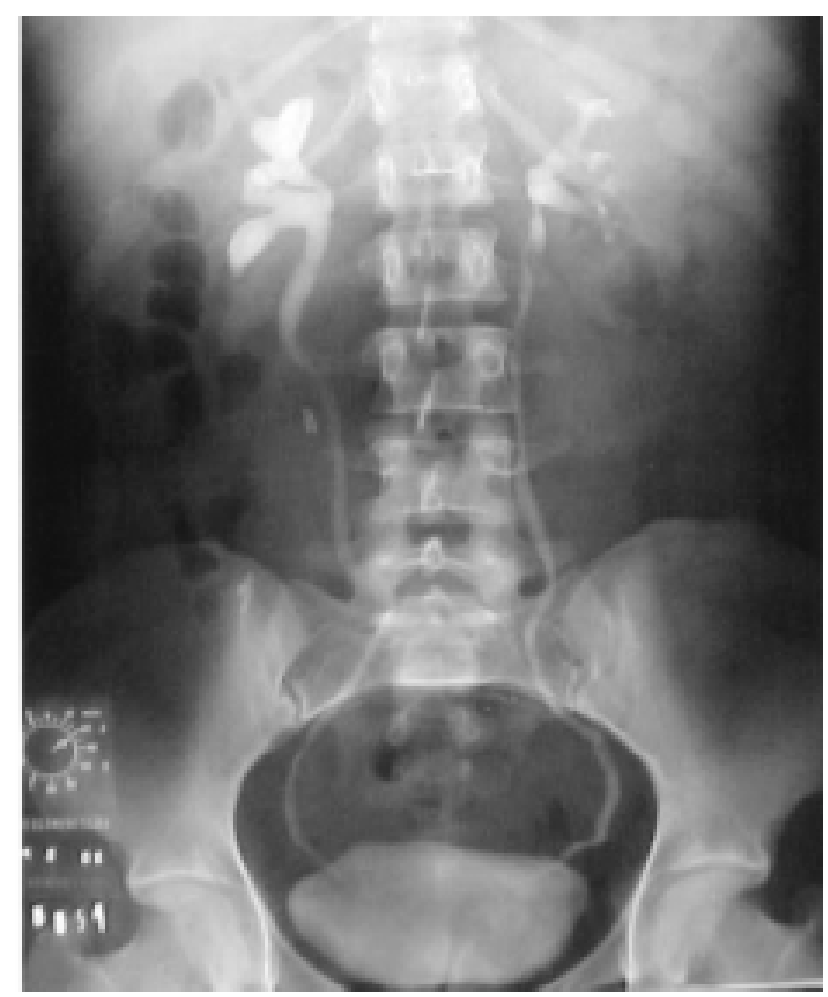

Figure 3 - Intravenous pyelogram within 18 months of followup, showing a reduction in the right ureter dilation and in the pyelocalyceal system, and the presence of metallic clips.

laparoscopic approach. In 4 cases, patients presented retroperitoneal fibrosis, one case was due to ovarian disease, and one case was the ovarian vein syndrome, the latter was the first case reported in literature on a patient submitted to a laparoscopic surgery management.

In 1998, Marcovich \& Wolf Jr. (4) published the second case of ovarian vein syndrome managed by ureterolysis and ovarian vein laparoscopic resection, highlighting the benefits of this technique, such as the diagnostic value of direct inspection of pathologic anatomic conditions, the low postoperative morbidity related to pain reduction, and the excellent cosmetic results.

Owing to its simplicity, low morbidity, and good results attained, the laparoscopic approach represents a good option for the surgical management of this syndrome.

\section{REFERENCES}

1. Hubmer G: The ovarian vein syndrome. Eur Urol. 1978; 4:263-8.

2. Dykhuizen RF, Roberts JA: The ovarian vein syndrome. Surgery Gynec Obstet. 1970; 130:443-52.

3. Elashry OM, Nakada SY, Wolf Jr JS, Figenshau RS, McDougall EM, Clayman RV: Ureterolysis for extrinsic ureteral obstruction: a comparison of laparoscopic and open surgical techniques. J Urol. 1996; 156:1403-10.

4. Marcovich R, Wolf Jr JS: Laparoscopy for the treatment of positional renal pain. Urology 1998; 52:3843.

Received: October 10, 2002

Accepted after revision: January 24, 2003

\footnotetext{
Correspondence address:

Dr. Arakén Almeida

Rua do Paissandu, 667 / 13

Recife, PE, 52010-000, Brazil

Fax: + 5581 3222-2024

E-mail: arakenaa@elogica.com.br
} 